\title{
Negative right ventricular diastolic pressure after operation for pulmonary valve stenosis: the phenomenon and its relation to volume load and conal contraction
}

\author{
REPHAEL MOHR, ARAM SMOLINSKY, ZVI ZISKIND, HOA TRAN QUANG, \\ DANIEL A GOOR
}

From the Department of Cardiac Surgery, Chaim Sheba Medical Centre, Tel Hashomer, Israel

SUMMARY The phenomenon of negative right ventricular diastolic pressure immediately after operation for relief of isolated pulmonary valve stenosis was investigated in 11 patients. Pressures in the right ventricle and pulmonary artery were measured with a catheter tip micromanometer. One patient had a negative right ventricular diastolic pressure before operation. At the end of operation right ventricular diastolic pressure was negative in all 11 patients. The greater the right ventricular hypertrophy, the lower were these diastolic pressures. Negative right ventricular diastolic pressure is thus common in patients after pulmonary valvotomy, but fluid administration may eliminate it. Negative right ventricular diastolic pressure may be the result of hypercontraction and reduced volume of the hypertrophied right ventricle after relief of right ventricular outflow tract obstruction.

Negative diastolic pressure mostly in the left ventricle has been demonstrated in animal and in human experiments, ${ }^{1-5}$ as well as in conditions such as mitral stenosis ${ }^{56}$ or after rapid exsanguination. ${ }^{78}$

Sabbah and Stein among others showed that negative diastolic pressures can also be demonstrated in the right ventricle. ${ }^{910}$ Diastolic pressure in the right ventricle of a patient with pulmonary stenosis may be normal or raised when severe obstruction or right ventricular failure is present. ${ }^{11}$ Our incidental observation that negative right ventricular diastolic pressure was common after pulmonary valvotomy ${ }^{12}$ prompted us to more detailed study of right ventricular pressure after pulmonary valve operation.

\section{Patients and methods}

Eleven patients (aged 2-58, median $14 \cdot 7$ years)

Requests for reprints to Dr Daniel A Goor, Department of Cardiac Surgery, Chaim Sheba Medical Centre, Tel Hashomer 52621, Israel.

Accepted for publication 21 August 1985 undergoing elective operation for isolated pulmonary valve stenosis were studied prospectively. Table 1 shows their preoperative clinical characteristics and right ventricular catheterisation data. Preoperative symptoms included cyanosis in three, finger clubbing in three, effort dyspnoea in three, and congestive heart failure in two. Three of the patients were symptom free. Right ventricular hypertrophy was noted in 10 patients.

Mean right ventricular systolic pressure was 107.5 (52.5) $\mathrm{mm} \mathrm{Hg}$ (range 46-240). Preoperative right ventricular diastolic pressure ranged from -2 to $25 \mathrm{~mm} \mathrm{Hg}$ (mean $11.36(8.5) \mathrm{mm} \mathrm{Hg}$ ). Only one patient had negative diastolic pressure before operation. Three of the patients had appreciable conal contraction on preoperative angiograms, but all three showed relaxation of the right ventricular outflow tract during diastole. All operations were performed by means of an open heart technique. Dome shaped valves were treated by sharp commissurotomy up to the valve ring. Four patients who had dysplastic valves underwent partial or complete excision of the valve (valvectomy). A transannular patch was used in a patient with a dysplastic valve and small pulmonary annulus. Infundibular 
resection was used in one patient with infundibular muscular hypertrophy and important obstruction of the right ventricular outflow tract. In three patients who had either associated atrial septal defect or patent foramen ovale had it closed. We measured pressures in the right ventricle and pulmonary artery with a catheter tip micromanometer (Millar Instruments) immediately after discontinuation of cardiopulmonary bypass. The frequency response of the pressure sensor was almost flat $( \pm 2 \%)$ at $5 \mathrm{kHz}$. The zero baseline of the transducers was adjusted to atmospheric pressure before each set of measurements. Recordings were obtained on Electronics for Medicine VR-6. The frequency response of the recording system was flat to $700 \mathrm{~Hz}$.

Diastolic pressures were measured twice in the right ventricle; firstly after the end of cardiopulmonary bypass. At this stage the heart did not appear to be distended or collapsed and the level of the blood in the oxygenator was about the same as before onset of cardiopulmonary bypass (central venous pressure $(4-7 \mathrm{~mm} \mathrm{Hg})$. The second measurement was taken while the chest was still open, approximately 10 to 15 minutes later, after the patient's condition had stabilised and after an additional volume of blood (mean $10 \mathrm{ml} / \mathrm{kg}$ pump blood) had been administered. Preoperative and postoperative right ventricular pressures were compared by the paired Student's $t$ test.

\section{Results}

In all eleven patients postoperative right ventricular diastolic pressure was negative $(-14(7 \cdot 2)) \mathrm{mm} \mathrm{Hg}$ and significantly lower than the preoperative pressure $(p<0.001)$ (Table 2, Fig. 1). Pressures as low as $-28 \mathrm{~mm} \mathrm{Hg}$ were noted (Fig. 2). The negative diastolic pressures were measured in the body and in the infundibulum of the right ventricle. Pulmonary artery diastolic pressure was negative in three patients after pulmonary valvectomy (cases $1,3,4$ ) and in one after infundibular resection and transannular patching (case 7). The pressure in the right ventricle was negative during most of diastole. In all patients right ventricular diastolic pressure was lowest during the early phase of rapid ventricular filling (Fig. 3).

Volume load tended to reduce or eliminate the negative pressure (Fig. 4, Table 2). Negative diastolic pressures below $-10 \mathrm{~mm} \mathrm{Hg}$ were observed only in patients with preoperative right ventricular: left ventricular systolic pressure ratios higher than 0.9 (Fig. 5).

The subgroup of patients with low right ventricular: left ventricular ratios $(<0.9)$ had significantly higher postoperative diastolic right ventricular pressures compared with the subgroup in which the ratio was high $(-6.75(2 \cdot 9)$ vs $-18 \cdot 2$ (6) $\mathrm{mm} \mathrm{Hg})(\mathrm{p}<0.001)$.

-able 1 Characteristics of 11 patients before pulmonary valve operation

\begin{tabular}{|c|c|c|c|c|c|c|c|c|c|c|c|c|}
\hline $\begin{array}{l}\text { iase } \\
\text { lo }\end{array}$ & Age & Sex & Symptoms & $R V H$ & $\begin{array}{l}\text { Sys } B P \\
(\operatorname{mm} H g)\end{array}$ & $\begin{array}{l}R V \text { sys } \\
(\operatorname{mom} \mathrm{Hg})\end{array}$ & $\begin{array}{l}R V \text { dias } \\
(\mathrm{mm} H \mathrm{Hg})\end{array}$ & $R V \mid L V$ & $\begin{array}{l}\text { Subvalvar } \\
\text { obstruc }\end{array}$ & $\begin{array}{l}\text { Associated } \\
P F O\end{array}$ & $\begin{array}{l}\text { Dysplastic } \\
\text { valve }\end{array}$ & Operation \\
\hline 1 & 4 & $\mathbf{M}$ & Tiredness & + & 100 & 130 & 12 & $1 \cdot 3$ & - & - & + & $\begin{array}{l}\text { Valvectomy * and } \\
\text { transannular } \\
\text { patch }\end{array}$ \\
\hline 2 & 5 & $\mathbf{F}$ & $\begin{array}{l}\text { Cyanosis, } \\
\text { clubbing }\end{array}$ & + & 100 & 98 & 0 & 0.98 & - & $-(?)$ & + & Valvectomy \\
\hline 3 & $4 \cdot 5$ & $\mathbf{F}$ & $\begin{array}{l}\text { Cyanosis, } \\
\text { clubbing }\end{array}$ & ++ & 115 & 104 & 25 & -0.9 & - & + & + & Valvectomy \\
\hline 1 & 58 & $\mathbf{F}$ & $\begin{array}{l}\text { CHF, } \\
\text { dyspnoea }\end{array}$ & ++ & 120 & 120 & 10 & 1 & + & - & + & Valvectomy \\
\hline $\begin{array}{l}5 \\
5 \\
7\end{array}$ & $\begin{array}{l}2 \\
6.5 \\
15\end{array}$ & $\begin{array}{l}\mathrm{F} \\
\mathrm{M} \\
\mathrm{F}\end{array}$ & $\begin{array}{l}\text { CHF, } \\
\text { effort } \\
\text { dyspnoea }\end{array}$ & $\begin{array}{l}+ \\
+ \\
+\end{array}$ & $\begin{array}{l}102 \\
100 \\
120\end{array}$ & $\begin{array}{r}88 \\
100 \\
240\end{array}$ & $\begin{array}{l}22 \\
20 \\
20\end{array}$ & $\begin{array}{l}0.86 \\
1 \\
2\end{array}$ & $\begin{array}{l}- \\
+\end{array}$ & $\begin{array}{l}- \\
\overline{-}\end{array}$ & $\bar{z}$ & $\begin{array}{l}\text { Valvotomy } \\
\text { Valvotomy } \\
\text { Valvotomy and } \\
\text { infundibular } \\
\text { resection }\end{array}$ \\
\hline 3 & 6 & $\mathbf{M}$ & Cyanosis & $(-)$ & 118 & 46 & -2 to +4 & 0.39 & - & + & - & $\begin{array}{l}\text { Valvotomy and } \\
\text { incomplete } \\
\text { closure of PFO }\end{array}$ \\
\hline ) & 6 & $\mathbf{M}$ & - & + & 110 & 62 & 0 & 0.56 & - & - & - & $\begin{array}{l}\text { Valvotomy and } \\
\text { closure of ASD }\end{array}$ \\
\hline ) & 48 & $\mathbf{M}$ & $\begin{array}{c}\text { Dyspnoea, } \\
\text { palpitation }\end{array}$ & + & 126 & 134 & 2 & 1.06 & + & + & - & $\begin{array}{l}\text { Valvotomy and } \\
\text { closure of ASD }\end{array}$ \\
\hline $\begin{array}{l}\text { l } \\
\text { lean } \\
\text { iD) }\end{array}$ & $\begin{array}{r}7 \cdot 5 \\
14 \cdot 7 \\
\quad(16)\end{array}$ & $\mathbf{F}$ & Dyspnoea & + & 105 & $\begin{array}{l}60 \\
107 \cdot 5 \\
(52 \cdot 5)\end{array}$ & $\begin{array}{l}16 \\
11 \cdot 36 \\
(8 \cdot 5)\end{array}$ & $\begin{array}{l}0.57 \\
0.96 \\
(0.43)\end{array}$ & - & - & - & Valvotomy \\
\hline
\end{tabular}

Valvectomies were performed only in patients with dysplastic pulmonary valves.

HF, congestive heart failure; RVH, right ventricular hypertrophy on electrocardiogram; Sys BP, systemic blood pressure (systolic); RV sys, systolic right entricular pressure; RV dias, diastolic right ventricular pressure; PFO, patent foramen ovale. 


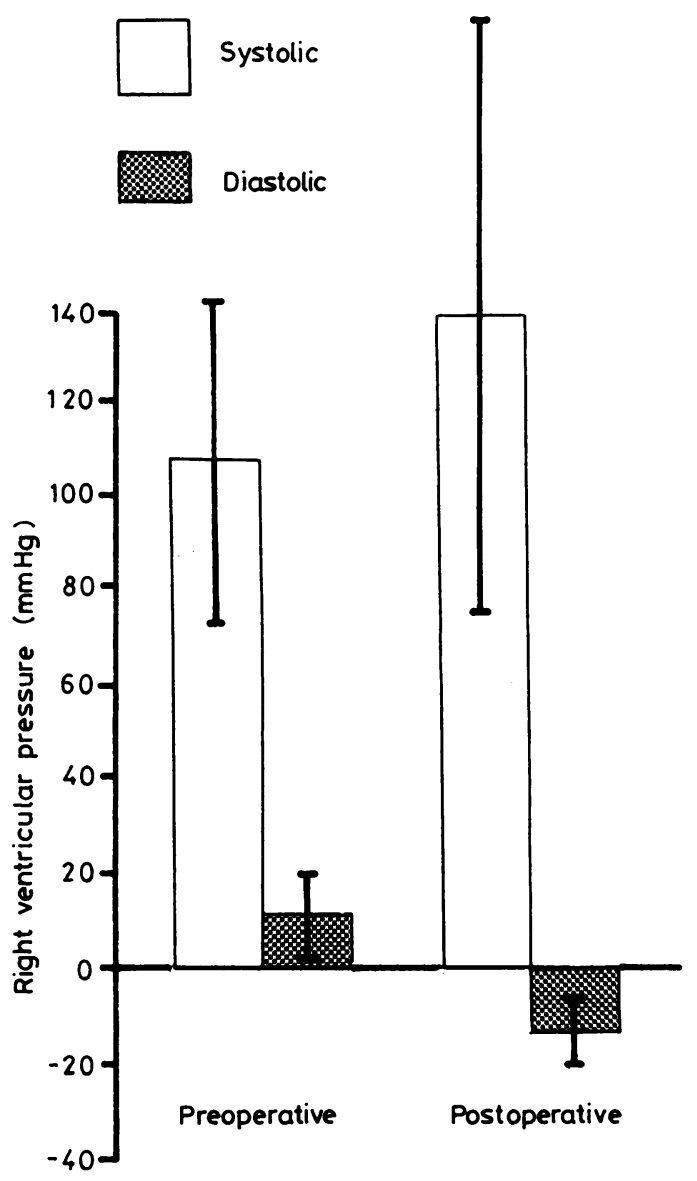

Fig. 1 Effect of pulmonary valve operation on right ventricular pressure.

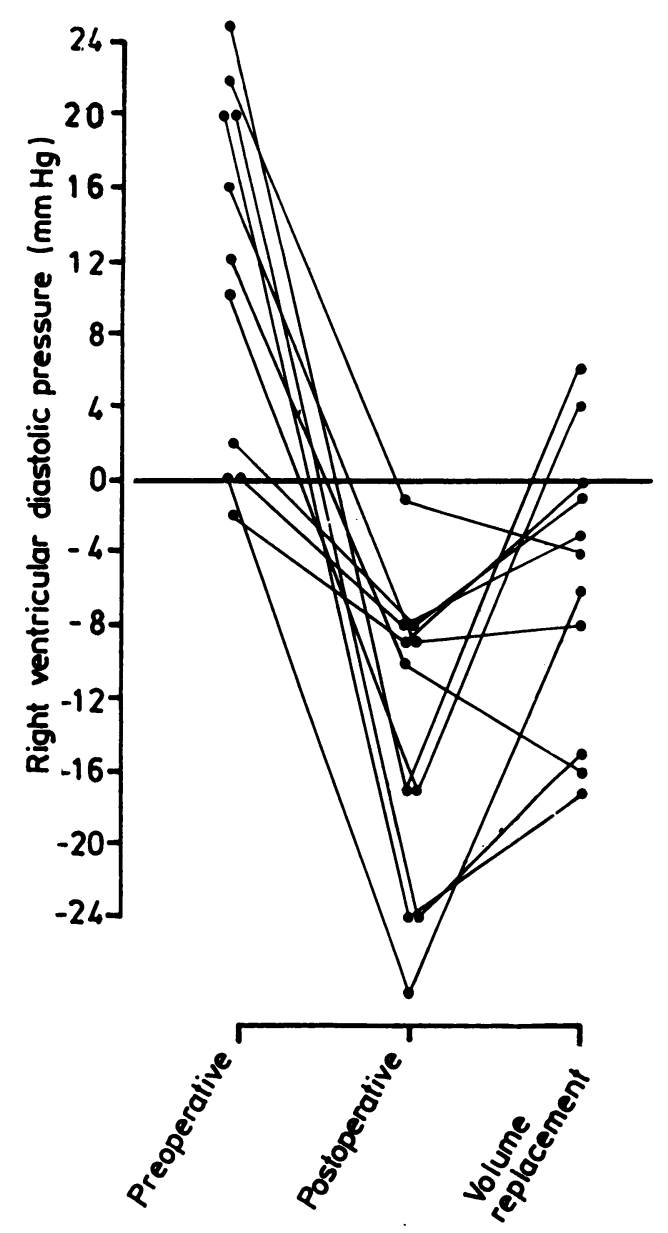

Fig. 2 Effect of pulmonary valve operation on minimum diastolic pressure in the right ventricle. Minimal diastolic pressure after administration of blood for volume replacement is also shown.

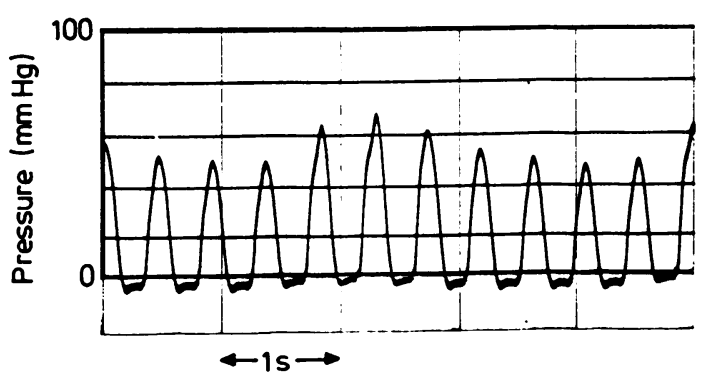

Fig. 3 Right ventricular pressure tracing after pulmonary valvotomy. 
(a)
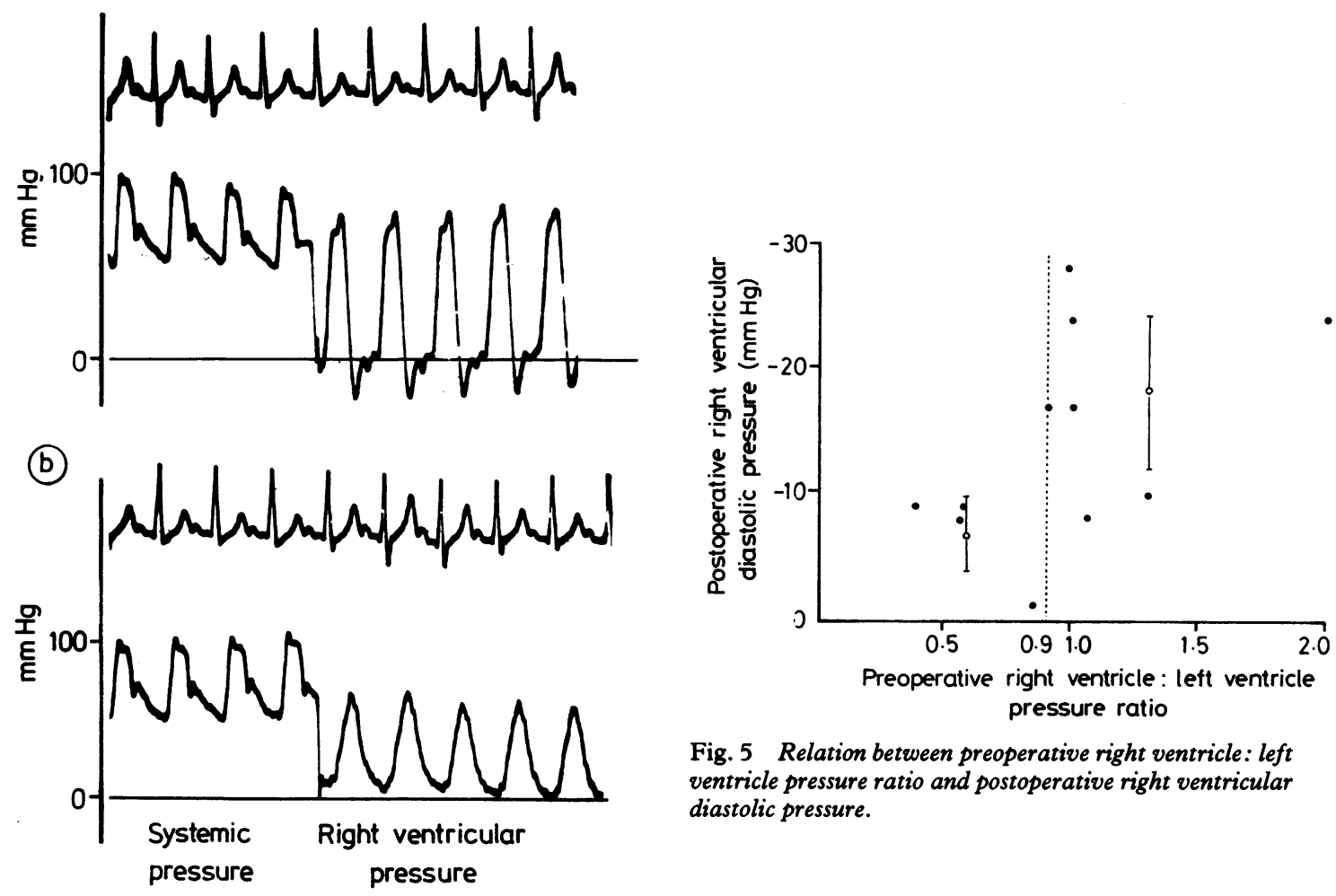

Fig. 5 Relation between preoperative right ventricle: left ventricle pressure ratio and postoperative right ventricular diastolic pressure.

Fig. 4 Increase of right ventricular diastolic pressure after volume replacement in a patient after pulmonary valvotomy. (a) After valvotomy and (b) after volume replacement.

able 2 Right ventricular and pulmonary artery pressures at end of cardiopulmonary bypass in 11 patients after pulmonary valvotomy

\begin{tabular}{|c|c|c|c|c|c|c|c|c|c|c|}
\hline \multirow{2}{*}{$\begin{array}{l}\text { ase } \\
\text { 'o }\end{array}$} & \multicolumn{2}{|c|}{$B P(m m ~ H g)$} & \multicolumn{2}{|c|}{$R V$ initial $(m m \mathrm{Hg})$} & \multicolumn{2}{|c|}{ Infundibulum $(\mathrm{mm} \mathbf{H g})$} & \multicolumn{2}{|c|}{ Pulmonary artery $(\mathrm{mm} \mathrm{Hg})$} & \multicolumn{2}{|c|}{$R V$ after volume load ( $\mathrm{mm} \mathrm{Hg}$ ) } \\
\hline & Sys & Dias & Sys & Dias & Sys & Dias & Sys & Dias & Sys & Dias \\
\hline $\begin{array}{l}1 \\
3 \\
3 \\
1 \\
5 \\
3 \\
1 \\
3 \\
1 \\
3 \\
1 \\
\text { lean (SD) }\end{array}$ & $\begin{array}{l}120 \\
110 \\
130 \\
110 \\
105 \\
110 \\
130 \\
101 \\
120 \\
107 \\
121 \\
115(9 \cdot 8)\end{array}$ & $\begin{array}{l}80 \\
80 \\
80 \\
80 \\
57 \\
70 \\
80 \\
70 \\
80 \\
90 \\
67\end{array}$ & $\begin{array}{l}120 \\
116 \\
200 \\
214 \\
207 \\
105 \\
285 \\
35 \\
111 \\
109 \\
31 \\
139 \cdot 3(78 \cdot 4)\end{array}$ & $\begin{array}{l}-10 \\
-28 \\
-17 \\
-17 \\
-1 \\
-24 \\
-24 \\
-9 \\
-8 \\
-8 \\
-9 \\
-14(8 \cdot 5)\end{array}$ & $\begin{array}{r}119 \\
200 \\
128 \\
200 \\
195 \\
\\
110 \\
75\end{array}$ & $\begin{array}{r}-10 \\
-17 \\
-12 \\
-1 \\
-18 \\
-8 \\
-6\end{array}$ & $\begin{array}{l}15 \\
30 \\
18\end{array}$ & $\begin{array}{r}-5 \\
-14 \\
-6\end{array}$ & $\begin{array}{l}118 \\
100 \\
130 \\
135 \\
113 \\
117 \\
170 \\
48 \\
100 \\
88 \\
38 \\
105 \cdot 1(37 \cdot 7)\end{array}$ & $\begin{array}{r}-16 \\
-6 \\
\\
4 \\
-4 \\
-15 \\
-17 \\
0 \\
-1 \\
-3 \\
-8 \\
-6.6(7 \cdot 2)\end{array}$ \\
\hline
\end{tabular}

P, systemic blood pressure; RV, right ventricular pressure; dias, diastolic; sys, systolic. 


\section{Discussion}

Postoperative right ventricular diastolic pressure was negative in all 11 patients operated upon. In nine of the eleven cases volume loading reduced the degree of the negative pressure in the right ventricle. This may indicate some degree of hypovolaemia in these patients. Indeed, exsanguination and hypovolaemia have been reported in association with the development of negative ventricular pressure. ${ }^{68}$

Hypercontraction of the hypertrophied right ventricle after relief of long standing overload may be the main factor producing negative pressure in the present series. This is supported by the lower right ventricular diastolic pressure in patients with the greater preoperative right ventricular hypertrophy (right ventricular:left ventricular ratios $>0.9$ ) (Fig. 5).

It has been shown that reduced end systolic volume is associated with negative diastolic ventricular pressures. ${ }^{23}$ It is also recognised that once pulmonary stenosis is relieved the contraction of the right ventricular conus is more complete, ${ }^{13}$ and this may result in further contraction of end systolic right ventricular volumes. Whether the main factor in producing negative ventricular diastolic pressure is hypovolaemia or hypercontractility, end systolic volume always seems to be reduced. ${ }^{1-8}$

We found negative diastolic pressures in the pulmonary artery after valvectomy or valvectomy with transannular patching. By causing pulmonary valve insufficiency these procedures may have a deleterious effect on the right ventricle. ${ }^{14}$

It has been suggested that negative diastolic pressures may be associated with a suction effect. ${ }^{2} 315$ Under such circumstances, the ventricles contract to a volume smaller than that of their "elastic equilibrium volume" and smaller than that achieved at rebound by "elastic recoil", and thus cause the negative pressure and its suction effect. ${ }^{2315}$ Deformation of some components of the ventricle during systole may produce the potential energy for an elastic recoil during diastole. ${ }^{115}$

It is clear that negative right ventricular diastolic pressure is common immediately after isolated pulmonary valvotomy and should be taken into account during volume loading at the end of cardiopulmonary bypass.
References

1 Rushmer RF, Crystal DK, Wagner C. The functional anatomy of ventricular contraction. Circ Res 1953; 1: 162-70.

2 Brecher GA. Experimental evidence of ventricular diastolic suction. Circ Res 1956; 4: 513-8.

3 Brecher GA, Kissen AT. Relation of negative intraventricular pressure to ventricular volume. Circ Res 1957; 5: 157-62.

4 Kraner JC, Ogden E. Ventricular suction in the turtle. Circ Res 1956; 4: 724-6.

5 Bloom WL, Ferris EB. Negative ventricular diastolic pressure in beating heart studied in vitro and in vivo. Proc Soc Exp Biol Med 1956; 93: 451-4.

6 Sabbah HN, Anbe DT, Stein PD. Negative intraventricular diastolic pressure in patients with mitral stenosis: evidence of left ventricular diastolic suction. Am Y Cardiol 1980; 45: 562-6.

7 Fowler NO, Couves C, Bewick J. Effect of inflow obstruction and rapid bleeding on ventricular diastolic pressure. F Thorac Cardiovasc Surg 1958; 35: 532-7.

8 Roberts WC, Brownlee WJ, Jones AA, Luke JL. Sucking action of the left ventricle. Demonstration of a physiologic principle by a gunshot wound penetrating only the right side of the heart. Am $\mathcal{F}$ Cardiol 1979; 43: 1234-7.

9 Sabbah NH, Stein PD. Negative diastolic pressure in the intact canine right ventricle; evidence of diastolic suction. Circ Res 1981; 49: 108-13.

10 Sabbah HN, Anbe DT, Stein PD. Can the human right ventricle create a negative diastolic pressure suggestive of suction? Cathet Cardiovasc Diagn 1981; 7: 259-67.

11 Moss AJ, Adams FH, Emmanouilides GC. Heart disease in infants, children and adolescents. Baltimore: Williams and Wilkins, 1977: 240.

12 Mohr R, Milo S, Smolinsky A, Goor DA. Right ventricular pressure drop 24 hours after open heart surgery for isolated pulmonary valve stenosis: the phenomenon and its surgical implication. Circulation 1981; 64 (suppl IV): 127.

13 Kittle CF, Batchelder TL, Miller DR. Postoperative monitoring of right ventricular pressures in cardiac surgery. Arch Surg 1960; 80: 39-45.

14 Ellison RG, Brown WJ Jr, Yeh TJ, Hamilton WF. Surgical significance of acute and chronic pulmonary valvular insufficiency. $\mathcal{F}$ Thorac Cardiovasc Surg 1970; 60: 549-58.

15 Brecher GA, Kolder H, Horres AD. Ventricular volume of non-beating excised dog hearts in the state of elastic equilibrium. Circ Res 1970; 19: 1080-5. 